\title{
LA CALETA (CÁDIZ) Y SUS DEFENSAS A LO LARGO DE LA MODERNIDAD
}

\section{LILYAM PADRÓN REYES | UNIVERSIDAD DE CÁDIZ}

\author{
ORCID iD: 0000-0002-8646-584X
}

\begin{abstract}
RESUMEN
Atendiendo al protagonismo gradual cobrado por la Bahía de Cádiz en el comercio atlántico nuestra propuesta pretende estudiar la evolución constructiva del sistema defensivo del enclave portuario gaditano de La Caleta durante los siglos XVI-XVIII. En nuestro análisis abordaremos los factores naturales, sociales y estratégicos que harían de La Caleta un espacio natural de referencia que actuaría como dinamizador de los intercambios (poblacionales, culturales), y en la misma medida de resguardo defensivo de la ciudad.
\end{abstract}

PALABRAS CLAVE

Defensas, Cádiz, La Caleta, época moderna, espacio atlántico.

\section{LA CALETA (CÁDIZ) AND ITS DEFENCES THROUGHOUT THE MODERN PERIOD}

\begin{abstract}
Taking into account the gradual role played by the Bay of Cádiz in Atlantic trade, our proposal aims to study the constructive evolution of the defensive system of the Cadiz port enclave of La Caleta during the 16th-18th centuries. In our analysis we will address the natural, social and strategic factors that would make La Caleta a natural reference space that would act as a catalyst for exchanges (population, cultural), and to the same extent as a defensive shelter for the city.
\end{abstract}

\section{KEYWORDS}

Fortifications, Cádiz, La Caleta, Modern Age, Atlantic area. 


\section{INTRODUCCIÓN}

$\mathrm{D}$ esde la época antigua la Bahía de Cádiz representó un puerto de referencia para el comercio y la navegación, la tradición náutica de Gadir o Gades sería favorecida por una localización geográfica estratégica que le ubicaría como entrenudo de conexión de los tráficos mediterráneos y atlánticos hacia África, Canarias, Europa e Indias.

Con el descubrimiento de América a partir de 1509, la inclusión de Cádiz en las rutas del comercio indiano dará paso a su protagonismo dentro de la estrategia oficial hispana desde el inicio de la Época Moderna. La relación de Cádiz con el espacio atlántico superaría el ámbito histórico de su territorio, transformándole poco a poco en el modelo de ciudad mercantil y portuaria que abriría nuevos horizontes y conexiones.

La supremacía alcanzada por Cádiz en el siglo XVIII no puede entenderse como una mera consecuencia de su gestión comercial u política, sino que respondería a otros factores de índole geográfica e histórica, que cobrarían una especial significación en que el entorno de la bahía gaditana cobrase una connotación trascendental en el marco de las políticas y prácticas de la monarquía hispana.

De ahí que persigamos como objetivo en nuestro trabajo: examinar el sistema defensivo de La Caleta (Cádiz) desde fines del siglo XVI y su evolución constructiva de acuerdo a las coyunturas imperiales hispanas a lo largo de la modernidad. La metodología a seguir comprenderá el análisis del espacio y el poder, así como la aplicabilidad en este ámbito de las perspectivas y categorías más habituales en los estudios de historia local y global, en el estudio de la estrecha relación entre el imaginario oficial y la configuración de los sistemas defensivos?

Al estudio del sistema de defensas de la bahía gaditana se han dedicado numerosas obras, orientadas especialmente en el análisis del dinamismo del puerto gaditano a lo largo de la época moderna atendiendo a las excelentes condiciones como fondeadero natural situado en el litoral atlántico de la península ibérica. En este sentido, hemos de destacar los trabajos

1 BARNEYWARF, Santa Arias. The Spatial Turn:Interdisciplinary Perspectives, London:Taylor \& Francis, 2008; HAUSBERGER, Bernd. Historia mínima de la globalización, México DF.: El Colegio de México, 2018. LUENGO, Pedro, MORALES MARTINEZ, Alfredo y GÁMEZ CASADO, Manuel. Mares fortificados. Protección $\gamma$ defensa de las rutas de globalización en el siglo XVIII. Sevilla: Editorial Universidad de Sevilla, 2018. 
de Víctor Fernández Cano sobre las defensas de Cádiz en la Edad Moderna ${ }^{2}$, María Gloria Cano Révora en torno al Real Cuerpo de Ingenieros (1697-1847) ${ }^{3}$, y José Antonio Calderón Quijano respecto a las defensas del Golfo de Cádiz en la época moderna ${ }^{4}$.

Tomando como base las obras referenciadas anteriormente, junto a la revisión de otras fuentes primarias y cartográficas localizadas en el Archivo General de Indias y el Archivo General de Simancas nos centraremos en el análisis del modelo defensivo de Cádiz a lo largo de la modernidad, con especial atención en el área de La Caleta ${ }^{5}$. Ello nos permitirá el estudio de la proyección globalizadora de un espacio que tendría implicaciones históricas más allá de sus fronteras. De esta forma, pretendemos contribuir a una nueva visión de aquellos actores y plazas que estarían llamadas a jugar un papel fundamental en la defensa y gestión del imperio español.

\section{LA CALETA (CÁDIZ) Y SU PAISAJE DEFENSIVO, SIGLOS XVI- XVII}

La vertiente atlántica andaluza sería una de las regiones más dinámicas y atractivas de Europa desde la Baja Edad Media. Varios factores interconectados permitieron su desarrollo económico. En primer lugar, contaba con una posición estratégica en las rutas del comercio internacional. Sus puertos eran lugares de paso obligatorio para aquellos comerciantes que conectaban los mercados del Mediterráneo con los del Atlántico ${ }^{6}$. Una de las zonas que más se beneficiaron de este impulso comercial fue la Bahía de Cádiz, que a lo largo del siglo XV se convirtió en un enclave de referencia, especialmente tras el salto definitivo con el desarrollo de la Carrera de Indias.

Siendo así, la defensa de la ciudad se convertiría en un asunto cada vez más apremiante para sus autoridades y el Consejo de Castilla antela continua amenaza de que las continuas amena-

2 FERNANDEZ CANO, Víctor. Las defensas de Cádiz en la Edad Moderna. Sevilla: Escuela de Estudios Hispanoamericanos, 1973.

3 CANO RÉVORA, María Gloria. Cádiz vel real Cuerpo de Ingenieros Militares (1697-1847). Cádiz: Servicio de Publicaciones de la Universidad de Cádiz, 1994.

4 CALDERON QUIJANO, José Antonio. Las defensas del Golfo de Cádiz en la Edad Moderna, Sevilla: Escuela de Estudios Hispanoamericanos, 1976.

5 BUSTOS RODRÍGUEZ, Manuel. Cádiz en el sistema atlántico. La ciudad, sus comerciantes $\gamma$ la actividad mercantil (16501830). Madrid: Sílex Ediciones 2005; ALONSO VILLALOBOS, Carlos y MÁRQUEZ CARMONA, Lourdes. El sistema portuario de la Bahía de Cádiz en época moderna a través de la cartografía histórica, en Fronteras de agua: las ciudades portuarias y su universo cultural (siglos XIV-XXI) (Comp.), Santiago de Compostela: Servicio de Publicaciones de la Universidad de Santiago de Compostela, 2016, PP.181-195; IGLESIAS RODRIGUEZ, Juan José. Las infraestructuras portuarias de la Bahía de Cádiz ante el reto del monopolio americano", Studia Histórica, 39, 2 2017, pp. 185-219; RUIZ GIL, José Antonio. Arqueología de la Bahía de Cádiz durante la Edad Moderna, Madrid: Editorial Académica Española, 2012.

6 RUIZ PILARES, Enrique José. El paisaje portuario en la bahía de Cádiz a finales de la Edad Media: los muelles fluviales, Riparia, 2 extra, 2019, pp.173-201. 
zas foráneas arremetiesen contra la villa gaditana y otros puertos importantes del sur de España ${ }^{7}$. De esta forma, a partir de la primera mitad del siglo XVI se comenzarían a dar los primeros pasos en estudiar el sistema de defensas, tras la llegada, en 1534, de Benedito de Rávena por encargo del monarca Carlos $V^{8}$. No obstante, el interés real por mantener a buen resguardo la ciudad, no sería materializado hasta 1554 tras la llegada del ingeniero militar italiano Juan Bautista Calvi con la ejecución los trabajos de fortificación centrados en la eficacia de la artillería moderna, y la puesta en valor de la escuela renacentista italiana de los frentes abaluartados?

En concreto, para la plaza de Cádiz, Calvi, proyectaría levantar tres baluartes orientados hacia el puerto para su defensa y otro en el interior de la ciudad, en el denominado muro de tierra. Por su parte cada uno de los baluartes quedarían conectados por lienzos de murallas que conformarían un cinturón defensivo alrededor de la villa. Pese a ello, la realidad demostraría que, pese a los sucesivos intentos reales por salvaguardar la bahía de Cádiz de los intereses foráneos. En 1596 la ciudad sería protagonista de un cruento ataque por parte de las fuerzas anglo-holandesas, que dejaría casi en ruinas sus escasas defensas, y pondría de manifiesto la vulnerabilidad de su bahía ante los enemigos externos ${ }^{10}$.

De esta forma, y tras los acontecimientos de indefensión el monarca Felipe II ordenaría el reforzamiento defensivo de la plaza de Cádiz. En este sentido, como bien afirmase Alicia Cámara Muñoz, el sistema de fortificación renacentista se convertiría en una premisa para la Corona hispana en ambas orillas del Atlántico, es decir, tanto en América como en la península, particularmente en la defensa de sus ciudades-puertos. De esta forma se crearía una especie de frontera, que mostraría todo un poder político y económico respecto a la condición de la guerra y las seguridades acerca de "un afuera del que solo cabía esperar la agresión"1 1 .

Así, con tal fin sería encargado a la ciudad de Cádiz por el Consejo de Guerra el ingeniero militar Cristóbal de Rodas ${ }^{12}$. Quien precisamente a días de su llegada emitiría al monarca

\footnotetext{
7 SÁNCHEZ SAUS, Rafael. Cádiz en la época medieval, en Historia de Cádiz, Madrid: Editorial Sílex, 2005.

8 FERNÁNDEZ CANO, Víctor. Las defensas de Cádiz...op.cit, p.5.

9 MARTÍNEZ LATORRE, Damián. Giovan Battista Calvi ingeniero de las fortificaciones de Carlos V y Felipe II (1552-1565), Madrid: Ministerio de Defensa, 2006.

10 BUSTOS RODRÍGUEZ, Manuel. El asalto anglo-holandés a Cádiz en 1596 y su contexto internacional, Cádiz, Servicio de Publicaciones de la Universidad de Cádiz, 1997.

11 CÁMARA MUÑOZ, Alicia. La fortificación de la monarquía de Felipe II, Espacio, Tiempo $\gamma$ Forma, Serie Vol., H. del Arte, T. 2, 1989 , P.77.

12 ARCHIVO HISTÓRICO DE LA NOBLEZA (AHN), PRIEGO, C.3, D.11. Real cédula de Felipe II al IX Conde de Priego, Pedro Carrillo de Mendoza, su asistente en la ciudad de Sevilla, dándole instrucciones para la fortificación de la ciudad de Cádiz.
} 
un pormenorizado informe acerca del estado de la ciudad. En el ámbito específico de La Caleta, destacaría la construcción del fuerte de Santa Catalina que servirían de salvaguarda a la ciudad gaditana. El castillo de Santa Catalina, proyectado en 1598, por Cristóbal de Rojas y finalizado en septiembre de 1621, tendría su utilidad como frente abaluartado. De planta pentagonal, en su frente oceánico presentaría una forma de estrella de tres puntas mientras que en el terrestre una muralla rectilínea en cuyo centro se dispone la puerta de acceso flanqueada por dos semibaluartes. La entrada se realizaría mediante un puente levadizo edificado sobre el foso. Si bien el proyecto de Rojas encontraría no pocos detractores para el área de La Caleta, especialmente por las autoridades y vecinos de la ciudad al considerar en lugar de un fuerte la construcción de murallas, en el transcurso de su construcción el propio ingeniero convencería al monarca Felipe II que el emplazamiento de dicho fuerte protegería y facilitaría la entrada de auxilios a la ciudad interior, y en la misma medida obstaculizaría que ningún ataque enemigo se hiciese con La Caleta y Rota ${ }^{13}$. Para su financiamiento inicial estimaba a la Corona unos 40.000 ducados.

Uno de los elementos constructivos más importantes de su entorno defensivo-marítimo, lo encontramos en su material constructivo, y concretamente en la conocida como piedra ostionera, un tipo de roca constituida a partir de distintos materiales, entre los que son visibles areniscas y restos de animales marinos fosilizados (conchas y cáscara de distintos moluscos, fundamentalmente). Siendo característica de la costa del entorno de la Bahía de Cádiz se extraería desde fines del siglo XVI, en canteras a cielo abierto en zonas próximas a la ciudad de Cádiz, a lo largo de sus playas y costas como en San Fernando, Chipiona, Sancti Petri y Chiclana de la Frontera. Sus diferentes tonos de marrón-que van desde el color miel claro hasta el marrón más tostado u oscuro-, su aspecto muy poroso, su peculiar textura arenisca, y la presencia de restos de conchas a lo largo de su superficie, son valores característicos que la hacen inconfundible a simple vista ${ }^{14}$. En espacios defensivos del entorno de La Caleta como Santa Catalina se presenta bien labrada en bloques ortogonales (sillares), generalmente en las plantas inferiores de fachada a modo de zócalo de base, que se deja vista a propósito- sin revestimiento posterior-, ennobleciendo así esta zona del edificio.

A comienzos del siglo XVII ante las continuas hostilidades del resto de imperios europeos, especialmente Inglaterra y los Países Bajos, junto a las continuas peticiones de las ciudades

13 FERNÁNDEZ CANO, Víctor. Las defensas de Cádiz...op.cit, pp.45-46.

14 Cf. DOMINGUEZ-BELLA, Salvador. Geología en el entorno de la ciudad de Cádiz, Rampas, 10, 1998, pp.117-130. 


\section{LILYAM PADRÓN REYES}

de Cádiz y Sevilla se tomaría la decisión por el Consejo de Guerra de ampliar la fortificación de Santa Catalina en La Caleta, y aportar unos 12.000 ducados para gastos de defensa y fortificación del entorno gaditano ${ }^{15}$. De esta forma se acometería la ampliación en Santa Catalina, particularmente con dos cortinas a cada lado por mandato del gobernador de la ciudad, Alonso de Noguera. En 1625, se encontraría cerrada su fortaleza con una muralla firme y alta de ocho pies de grueso, sus parapetos y contrafuertes por la parte interior. Tras las sucesivas mejores se estimaría que la ciudad se encontraba en defensa ante las noticias que vaticinaban un nuevo ataque de la Armada inglesa ${ }^{16}$. En las postrimerías del siglo XVII unido a su uso defensivo se agregaría un espacio sacro, con la construcción en 1693 de una capilla dedicada a Santa Catalina de Alejandría y a la Purísima Concepción.

Por su parte, en el extremo sur de La Caleta encontramos el pequeño islote de San Sebastián donde existen noticias y evidencias materiales que localizan un templo dedicado al dios Crono encuadrado cronológicamente en las épocas protohistórica y romana ${ }^{17}$. Más tarde desde 1613, sería instalada una torre atalaya construida a cargo de Juan de la Fuente Hurtado con una doble función: puesto artillero y faro, que señalaría la entrada de la Bahía de Cádiz $^{18}$. Al respecto, Agustín de Horozco, apuntaría,

Sobre la bóveda más alta de la torre había otro capitelillo, en forma de linterna, adonde en la hora que ya el día declina al ocaso y entra la negra noche se ha continuamente hecho y hace un pequeño fuego de alquitrán o de leña chamiza seca y delgada, fácil de se emprender por el guarda o atalaya que de esto tiene cargo, y al punto que esta llama es vista, luego se hace otra tal en la torre del almadraba de Hércules, y en el castillo de Sancti Petri, y desde él va por las demás torres hasta el Estrecho de Gibraltar, reino de Granada, Murcia, Valencia, Aragón y Cataluña, y otras costas en un instante ${ }^{19}$.

Para su financiamiento se establecería el impuesto de la "sisa del pescado", es decir, de cada libra de pescado obtenido de la costa se destinaría un maravedí para el sostenimiento de

15 ARCHIVO GENERAL DE SIMANCAS (AGS). PTR, LEG,85, DOC.186. Carta de la ciudad de Sevilla a Felipe II sobre la fortificación de Cádiz y su bahía, y la barra de Sanlúcar, 1597.

16 FERNÁNDEZ CANO, Víctor. Las defensas de Cádiz...op.cit, pp.73-74.

17 GÓMEZ MUÑOz, María Soledad. La isla sagrada de Venus Marina. un antiguo referente sacro para la navegación en la Bahía de Cádiz. Rampas, 20, 2018, pp.129-146.

18 GULLÓN ABAO, Alberto. Entre la defensa, el aviso y la vigía. Construcciones para el "emporio del orbe", en ELIAS CARO, Jorge y ROMAN ROMERO, Raúl, Museos: entre la historia y los patrimonios, Santa Marta, Asociación Colombiana de Estudios del Caribe (ACOLEC), pp.171-180.

19 HOROZCO, Agustín de. Historia de Cádiz. Cádiz, Servicio de Publicaciones de la Universidad de Cádiz, 2017. 
las llamadas "torres de la mar"20. Encontrándose así dentro de la jurisdicción de la ciudad las torres atalayas de Santi Petri, Hércules y San Sebastián ${ }^{21}$.

Figura 1

Planta de la ciudad de Cádiz. 1609

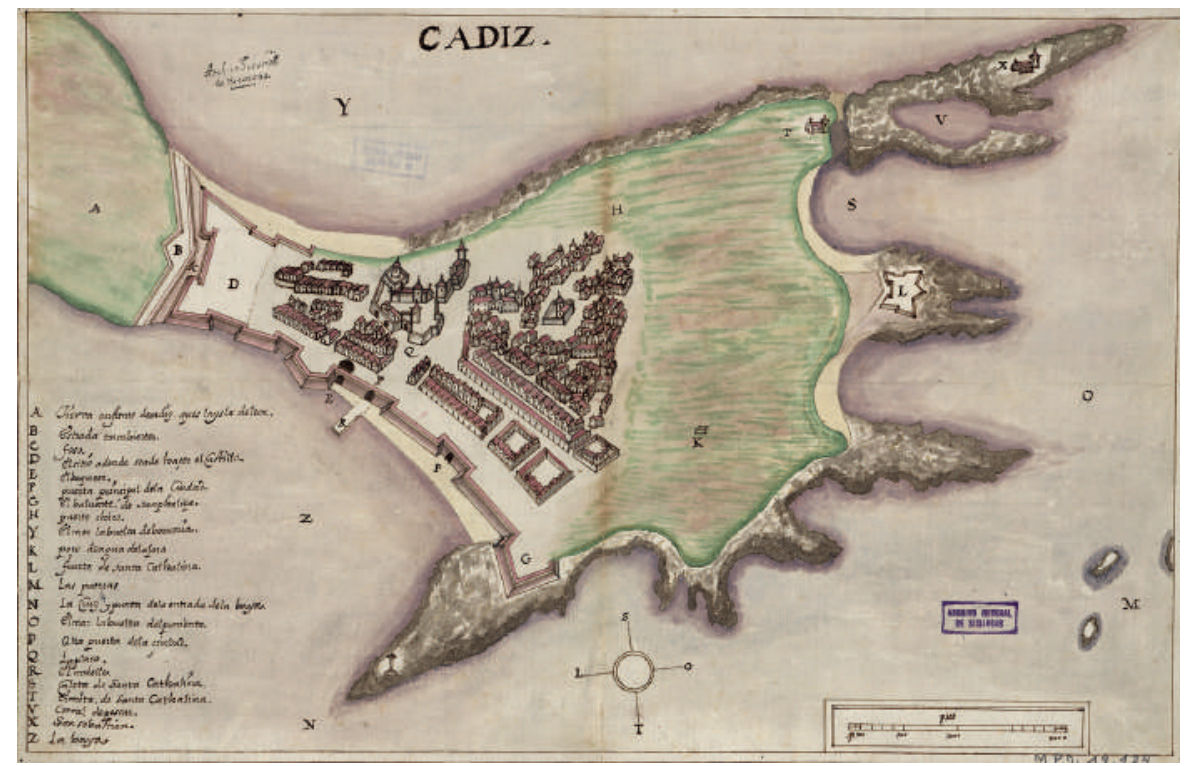

En el transcurso del siglo XVII las defensas de la ciudad se mantendrían alertas ante cualquier incursión externa. En conjunto a las fortificaciones, encontraremos en su presidio dos compañías que en total sumarian unos 114 soldados, que repartidos entre todos los puestos defensivos se encargarían de resguardar y mantener en defensa sus fortificaciones y murallas. No obstante, tras su viaje por Andalucía, y especialmente por Cádiz el Conde de Rastrillo, en 1647, haría participe a la Corona en su informe sobre la penosa situación del sistema defensivo gaditano y las pésimas condiciones de su guarnición ante los problemas económicos y el desabastecimiento de piezas de artillería y pertrechos del Presidio de Cádiz ${ }^{22}$.

Pese a ello, su puerto ganaría cada vez un mayor protagonismo en la Carrera de Indias en detrimento del monopolio sevillano, y ello incidiría directamente en que al finalizar el siglo XVII

20 AGS, SGU, Leg.993. Junta celebrada en Cádiz, 31 de agosto de 1629.

21 FERNANDEZ CANO, Víctor. Arquitectura militar de Cádiz en tiempos de los asaltos ingleses, Anuario de Estudios Americanos, 43, 1966, pp.8-11.

22 FERNANDEZ CANO, Víctor. Las defensas de Cádiz...op.cit, pp.84-86. 


\section{LILYAM PADRÓN REYES}

la ciudad contase con una serie de castillos, baluartes y sistema de murallas que asegurasen la estabilidad territorial de la Corona hispana. En la ciudad y sus territorios adyacentes se instalarían emigrantes venidos de otras zonas de la península y otras partes de Europa seducidos por el auge económico y los beneficios de su actividad mercantil, que se traducirán, asimismo, en una apremiante necesidad de abundante mano de obra, y el crecimiento en paralelo, de su burguesía mercantil que no pararía de enriquecerse con los cuantiosos dividendos obtenidos del trato comercial ya fuese con el Mediterráneo o el Atlántico ${ }^{23}$. Siendo así, el puerto de Cádiz se convertiría paulatinamente en un espacio clave para la gestión en materia económica y defensiva de la monarquía española, y en consecuencia se intentaría reforzar el sistema defensivo de la ciudad ante las nuevas premisas que marcarían su protagonismo en el monopolio indiano.

\section{EL PERFECCIONAMIENTO DE UN CONCEPTO DEFENSIVO, SIGLO XVIII}

El acontecimiento del siglo XVIII significaría la consolidación de Cádiz como plaza fuerte. Con antecedentes tan influyentes no se hizo esperar la Real Cédula de 12 de mayo de 1717 que ordenaba el traslado de la Casa de la Contratación y del Consulado de Sevilla a la ciudad de Cádiz. Ello llevaría una fuerte transformación del marco gaditano y su Bahía; no sólo por el conjunto de instituciones que se asentaron desde Sevilla, sino porque aparecieron una serie de reformas con la nueva dinastía borbónica que pretendían reestructurar la actividad mercantil y militar en el entorno ${ }^{24}$.

A tales efectos, se acometerían numerosas mejoras en el sistema defensivo de la ciudad, entonces distribuido en cuatro Frentes: Frente de la Tierra, Frente de La Caleta, Frente de Poniente y Frente de Bahía ${ }^{25}$. Asimismo, en la misma línea, encontramos pequeños baluartes como la Candelaria, los Mártires, Santiago, Santa Cruz, San Pedro, San Pablo o del Orejón y San Felipe que servían para reforzar la defensa del puerto de la ciudad de Cádiz de un extremo a otro todo en los puntos más vulnerables. La estructura de las murallas desde el punto de vista del análisis de los componentes, se clasificaría en dos grupos: baluartes y cortinas.

Como elemento fundamental en esta nueva etapa de fortificación que se abría para el espacio gaditano, se constituiría en diciembre de 1727 la llamada "Junta de Murallas" o “Real Junta de

23 BUSTOS RODRÍGUEZ, Manuel. Cádiz en el sistema atlántico: la ciudad, sus comerciantes $\gamma$ la actividad mercantil (16501830), Madrid: Sílex, 2005, pp.70-75.

24 CRESPO SOLANA, Ana. El comercio y la armada de la monarquía: la Casa de Contratación y la Intendencia General de la Marina de Cádiz, 1717-1750", en Cuadernos Monográficos del Instituto de Historia y Cultura Naval. 39, 2001, pp.63-78. 25 FERNANDEZ CANO, Víctor: Las defensas de Cádiz...op.cit, p.142. 
Fortificaciones" que tendría entre sus objetivos la realización de las obras de fortificación, así como el cobro de los impuestos a productos como el vino y vinagres con el fin de costear todo el perfeccionamiento del sistema de murallas ${ }^{26}$. El concepto de defensa heredado desde tiempos de Felipe II urgía ser reemplazado por un modelo más eficaz, que respondiera a las necesidades de controlar las zonas estratégicas, y se adaptase a las características del territorio en cuestión.

\section{Figura 2}

\section{Plano del castillo de San Sebastián de la Plaza de Cádiz. 1770}

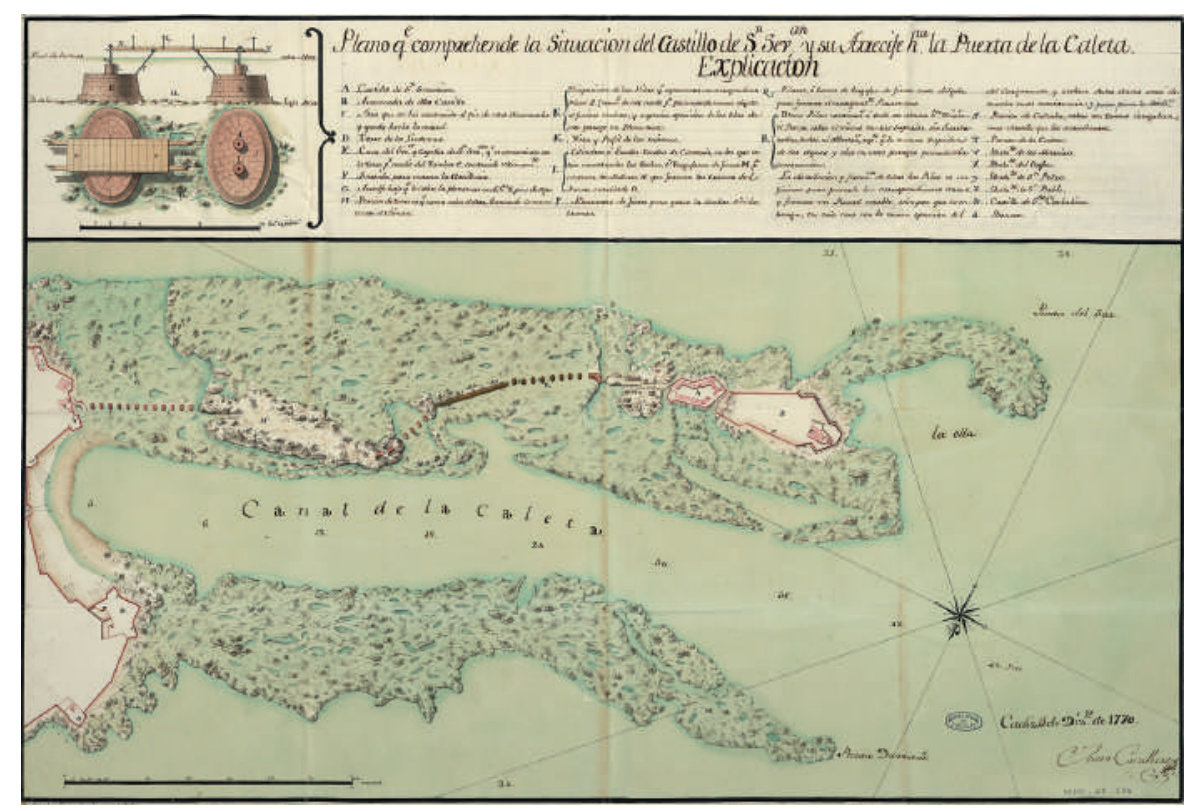

Con el encargo de modernizar y llevar a la práctica la nueva concepción ilustrada en el ámbito defensivo numerosos miembros del Real Cuerpo de Ingenieros desarrollarían su labor en la ciudad de Cádiz. En este sentido, llegarían a la ciudad a lo largo del siglo XVIII numerosos ingenieros militares, entre los que cabría destacar nombres como: Ignacio Salas, Silvestre Abarca, Enrique Le Gallois, Juan Martín Cermeño y José Barnola ${ }^{27}$. Dichos ingenieros tendrían a su cargo las principales transformaciones y proyectos defensivos en el periodo comprendido entre 1706-1799. El cuerpo de ingenieros tendrían a su cargo el estudio y construcción de un moderno sistema en el plano de la artillería, donde se ejecutarían mejoras, proyectándo-

26 CANO REVORA, Gloria. Cádiz y el real Cuerpo de Ingenieros Militares (1697-1847). Cádiz: Servicio de Publicaciones de la Universidad de Cádiz, 1994, Pp.35-36.

27 CRUZ FREIRE, Pedro. Un ingeniero militar al servicio de la monarquía: Silvestre Abarca, Sevilla: Athenaica. 2017; LÓPEZ HERNÁNDEZ, Ignacio y CRUZ FREIRE, Pedro. Ingeniería e ingenieros en la monarquía hispana, Sevilla: Servicio de Publicaciones de la Universidad de Sevilla, 2017. 
se trincheras de apoyo cada vez más cercanas a las murallas, y por consiguiente la artillería se ubicará en puntos cada vez más cercanos, con el objetivo de alcanzar mejores ángulos a batir al enemigo, teniendo en cuenta las circunstancias en el abastecimiento de víveres y municiones, así como la posibilidad de recibir refuerzos ${ }^{28}$.

En particular, para la zona de La Caleta, como gran novedad a partir de 1706 sería edificado el anterior castillo de San Sebastián, como parte de las nuevas políticas y prácticas de la Monarquía hispana. Su fortaleza construida con piedra ostionera presentaría una planta poligonal de nueve lados. El perímetro amurallado estaba provisto de diferentes parapetos destinados a la artillería y de un foso que podía salvarse mediante dos puentes levadizos. En el espacio situado frente al foso se construiría una plaza de armas destinada a defender toda la isla. El lado sur no sería fortificado al confiar en sus defensas naturales. Sus muros formarían una figura alargada de este a oeste, con ángulos entrantes y salientes. Durante esta primera etapa para acceder al castillo sería necesario que la guarnición esperase la marea baja para acceder desde la Puerta de La Caleta ${ }^{29}$.

\section{Figura 3}

Vista para hacer estable la comunicación del castillo de San Sebastián de Cádiz de la Plaza de Cádiz, con el proyecto que se aumenta al camino provisional que se hizo el año de 1773

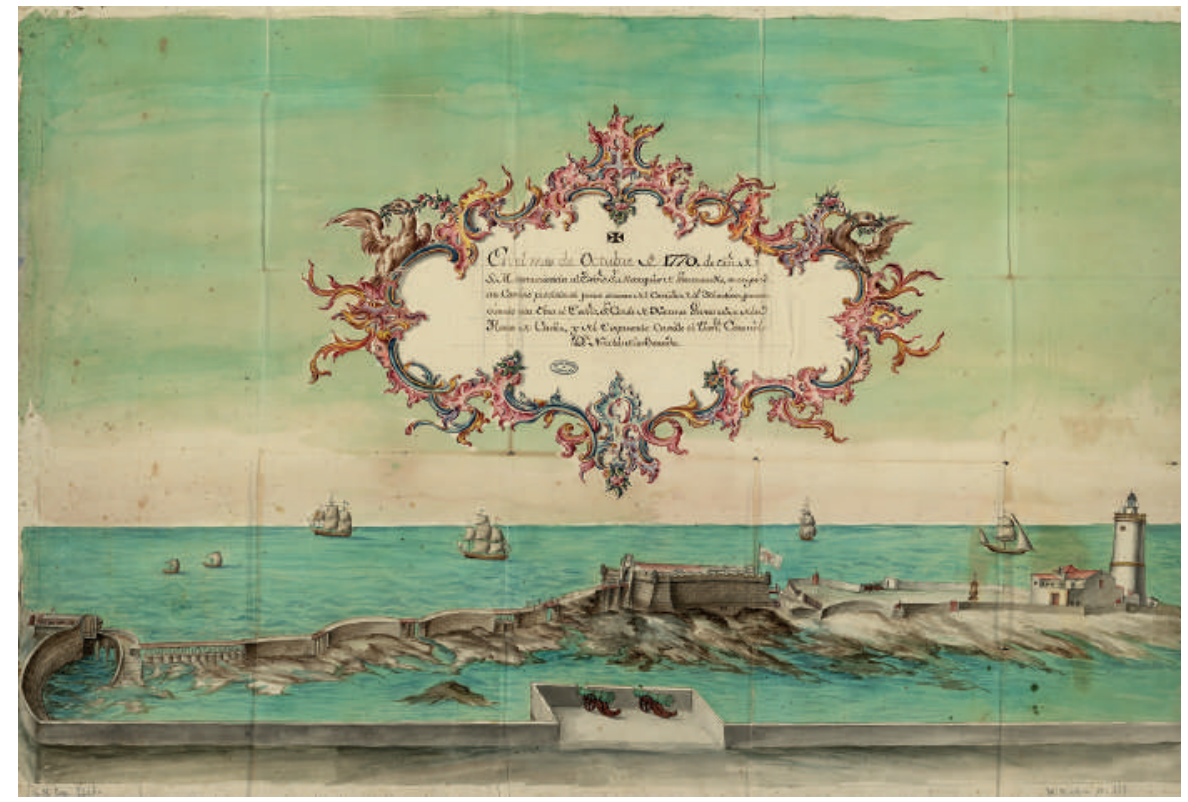

Fuente: AGS, MPD, sig.11/139

28 DE LIZAUR, A. La ilustración en Cataluña: la obra de los Ingenieros Militares, Madrid: Ministerio de Defensa. 2010 , p.481 29 FERNANDEZ CANO, Víctor: Las defensas de Cádiz...op.cit, pp.147-149. 
Los castillos de San Sebastián y Santa Catalina defenderían la entrada de La Caleta, y en opinión de Ignacio Sala serviría a buen resguardo de la ciudad para la provisión de suministros en caso cualquier ataque a la plaza. De esta forma, se preveía que pudiese ser objeto de un desembarco enemigo, y en tal efecto en sus primeros proyectos no consideraba una premisa el aumentar la dotación de su artillería, estimada en unos diecisiete cañones, especialmente localizados en la avanzada de San Sebastián, a los costados de la torre, en caso de que lanchas bombardas se aproximasen a la ciudad ${ }^{30}$.

Figura 4

\section{Plano de La Caleta en la plaza de Cádiz (1766)}

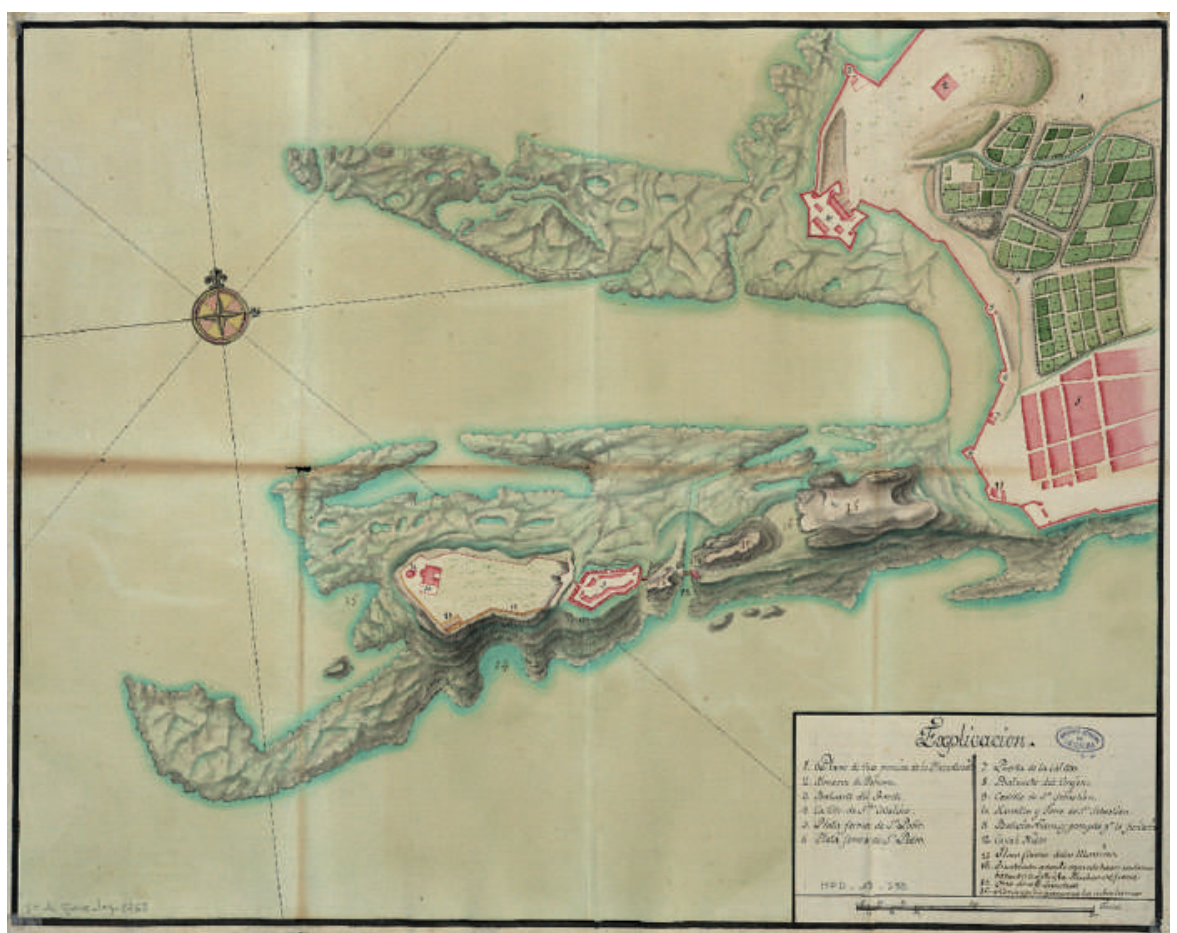

Fuente: AGS, SGM, leg. 3265

En el transcurso del siglo XVIII, no solamente sería de interés el proyecto para San Sebastián, sino también las numerosas mejoras acometidas en el castillo de Santa Catalina, especialmente estudiadas por el marqués de la Victoria a partir de 1762 ante el temor de un nuevo asalto a la ciudad por las bombardas de navíos extranjeros ${ }^{31}$. La singularidad defensiva del área de La Caleta, unido a los factores naturales y geográficos conseguirían

30 FERNANDEZ CANO, Víctor: Las defensas de Cádiz...op.cit, p. 149.

31 FERNANDEZ CANO, Víctor. Ibídem, p.157. 


\section{LILYAM PADRÓN REYES}

mantener en defensa y resguardar de posibles ataques externos al emporio gaditano. En este sentido el sistema defensivo de Cádiz servirá de ejemplo para la arquitectura militar americana $^{32}$. Y en gran parte, la movilidad de los ingenieros militares encargados de transmitir dichos conocimientos contribuiría notablemente a estrechar la relación atlántica a través de la Carrera de Indias, y por consiguiente en sus transferencias culturales, politicas y sociales a lo largo de la época moderna.

\section{REFLEXIONES FINALES}

En el transcurso de la modernidad, y a partir del cambio dinástico en España, un nuevo período de conflictos y reformas asomaría sus luces sobre la monarquía hispana. En el intento de un mayor y mejor control sobre sus territorios coloniales, se adoptarían una serie de medidas y políticas ilustradas, que pondrían de manifiesto su interés por conocer a profundidad el funcionamiento económico, político y militar del imperio, a la vez, que intentarían frenar el impulso de sus enemigos europeos, especialmente Inglaterra.

Las nuevas directrices serían gestionadas e inspeccionadas por un cuerpo de ingenieros militares que formados en las academias militares tendrían a su cargo la importante misión de perfeccionar y adaptar el entorno defensivo gaditano según las nuevas transferencias científicas y militares que marcarían el reformismo borbónico. De esta forma se iniciaría todo un complejo proceso, que ejecutado en varias etapas conseguiría estructurar un plan de defensa local, sustentado en las mejoras estratégicas que trasladarían a Cádiz la concepción del arte militar ilustrado basado en la mejora de su artillería, y en el máximo aprovechamiento de sus ventajas naturales siempre advirtiéndose que las acciones desarrolladas representasen el menor perjuicio económico para los intereses reales.

32 CAPEL, Horacio; SÁNCHEZ, Joan-Eugeni y MONCADA, Omar. De Palas a Minverva. La formación científica v la estructura institucional de los ingenieros militares en el siglo XVIII. Barcelona: Editorial Serbal, 1981. 